\section{ECCOMAS}

\section{Proceedia}

COMPDYN 2021

$8^{\text {th }}$ ECCOMAS Thematic Conference on Computational Methods in Structural Dynamics and Earthquake Engineering

M. Papadrakakis, M. Fragiadakis (eds.) Streamed from Athens, Greece, 28 - 30 June 2021

\title{
CYCLIC TEST OF A PRECAST BRIDGE COLUMN FOR SUSTAINABLE BRIDGE DESIGN
}

\author{
Natalia Reggiani Manzo ${ }^{1}$, and Michalis F. Vassiliou ${ }^{1}$ \\ ${ }^{1}$ ETH Zürich \\ Institute of Structural Engineering \\ Stefano-Franscini-Platz 5, 8093 Zürich, Switzerland \\ \{reggianimanzo,vassiliou\}@ibk.baug.ethz.ch
}

\begin{abstract}
In seismic regions, more often than never the dogma that bridge columns need to be firmly connected to the ground leads to huge pile foundations that require as much concrete as the superstructure. This is clearly a non-sustainable design method. To reduce the foundation design moment and possibly avoid the piles foundation, it has been proposed to let the bridge columns uplift and rock.

This paper presents quasi-static testing of a 1:5 scale precast restrained rocking bridge column exhibiting negative stiffness. The proposed system is resilient, able to achieve limited to no damage during design earthquakes. It allows prefabrication and quick on-site assembly, which reduces the on-site construction time and traffic impact.

As part of this experimental campaign, quasi-static cyclic tests were carried out on a reinforced concrete column allowed to rock on its interface with the foundation and cap-beam. An unbonded tendon was adopted to restrain the columns. The tendon was connected in series to a Belleville spring system to keep the overall post-uplift stiffness of the system negative. Large drifts lead to stress concentrations at the ends of the columns, therefore they were protected by steel jackets.

The column was subjected to drift ratios up to $15 \%$. The results show that it returned to its original position with negligible to no residual displacement.
\end{abstract}

Keywords: rocking bridges, Accelerated Bridge Construction, sustainable seismic design, precast bridges 


\section{INTRODUCTION}

Accelerated Bridge Construction (ABC) has emerged as a convenient method to reduce onsite construction time and traffic impact, as well as providing elements of higher quality due to its prefabrication offsite [1-23].

Within $\mathrm{ABC}$ two seismic design methods exist: (a) emulating connections of conventional reinforced concrete structures by creating fixed connections of the precast elements with cast in situ concrete or, (b) letting the precast elements rock by adopting dry connections combined with prestressed or posttensioned unbonded tendons passing through the columns. The advantage of the former method is that it results in bridges that behave like the traditional cast in place ones, this it is an established and easily acceptable technology. The advantage of the latter method is that it is more resilient as it presents minimal damage and residual displacement. Some of the techniques developed to emulate connections are: bar coupling [6, 7], pocket and socket connections [5, 10, 21, 23], and grouted duct connections [9, 22, 23].

As an alternative to emulated connections, rocking systems provide the additional advantage of reducing residual displacements and damage after the earthquake event ceases. Priestley and Tao [1] and Stone et al. [2] studied the behavior of precast posttensioned beam columns designed to rock in the connections. Mander and Cheng [13] developed the Damage Avoidance Design methodology for bridge piers, introducing the concept of precast posttensioned elements to bridge systems. Following on, Hewes and Priestley [17] and Billington and Yoon [18] also explored the adoption of posttensioned rocking elements to segmental columns.

To control design displacements, researchers proposed introducing energy dissipation devices to the system. Davis et al. [3], Finnson [4], Thonstad et al. [11] and Thonstad et al. [12] conducted an experimental campaign exploring the behavior of prestressed rocking piers with mild reinforcing bars connecting the foundation and column, and/or column and cap beam, which provided energy dissipation. With similar goal, Marriott et al. [20], Guerrini et al. [8], White and Palermo [24] and Mashal and Palermo [14] explored rocking piers equipped with external energy dissipaters.

Sideris et al. [25-27] also proposed a posttensioned segmental column with a rockdominant connection at the bottom, and intermediate slip-dominant connections, which provided energy dissipation with low damage.

The works mentioned above led to the development of systems with small residual displacements and low damage after a ground motion excitation. Hence, they succeed in the goal of resilience. However, they result in foundation design moments that are on the same order with their plastic design counterparts. These design moments often require huge pile foundations which can comprise up to $50 \%$ of the total Reinforced Concrete used in the whole project. Aiming at decreasing the foundation design moments and obtaining a more sustainable system, it has been suggested either to not restrain the bridge columns at all [28-42] or to restrain them with flexible restraining systems [43-46]. In an effort to bring the concept of negative stiffness closer to practice, this paper presents quasi-static cyclic tests of a restrained RC concrete column exhibiting negative post-uplift stiffness. The column is allowed to rock freely on its interface with the foundation, while the cap beam and column are connected through a non-prestressed tendon in series with disc springs.

\section{BEHAVIOR OF NEGATIVE STIFFNESS BILINEAR ELASTIC SYSTEMS}

Rocking systems of negative stiffness present the Negative Stiffness Bilinear Elastic (NSBE) force deformation loop shown in Fig. 1, and discussed extensively in [30]. Up until uplift the system behaves linearly with a stiffness representing any deformability the system 
might present before uplifiting. After uplifting, the tangent stiffness becomes negative. The displacement capacity is defined not by material failure, but by the displacement where the restoring force becomes negative. Therefore, for an unrestrained rocking column the displacement capacity is equal to its width. One can increase it by equipping the column with extended curved ends [47-49] or by adopting a flexible restraining system. Herein, a flexible restraining system was adopted for the proposed column.

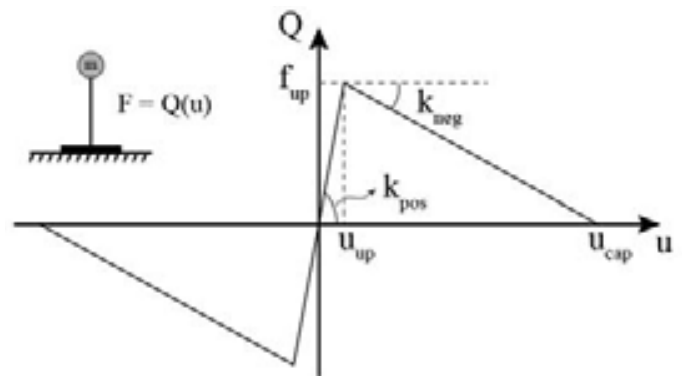

Figure 1: Characteristic Pushover Curve of a NSBE Oscillator (figure from [30])

\section{SPECIMEN DESIGN}

In the tests discussed in this paper, the restraining system of the column was designed to double the displacement capacity of the free rocking column, assuming that $u_{u p}$ is negligible. The system was composed of an unbonded tendon in series with disc ("Belleville") springs (Fig. 2). The disc springs were adopted to avoid yielding of the tendon in large displacements.

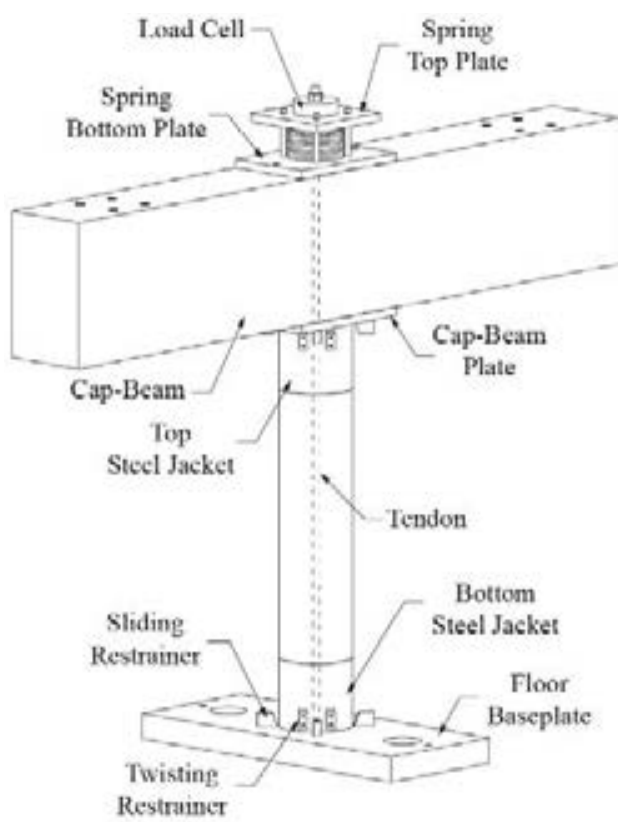

Figure 2: Specimen

The ungrouted tendon passed through the centerline of the column. One end was anchored in the bottom of the column, providing no connection between the foundation and the column. The other end was anchored above the beam, in series with the disc springs. No prestress loading was applied to the restraining system.

The columns were protected by steel jackets at their ends. The jackets comprised a steel tube welded to a circular end plate. Steel jackets were also used by $[11,14]$. However, in the tests discussed in this work, the stresses are expected to be smaller because of the springs. 
Steel plates were also fixed to the floor and to the cap beam to avoid damage due to stress concentrations. The plates were equipped with sliding restrainers, which limited the sliding motion of the column. A restrainer was also provided to avoid twisting of the columns. Fig. 2 presents the tested system, in which the elements discussed in this section are identified.

The geometry of the column is shown in Fig. 3-4 and follows from scaling to 1:5 a typical overpass bridge column.

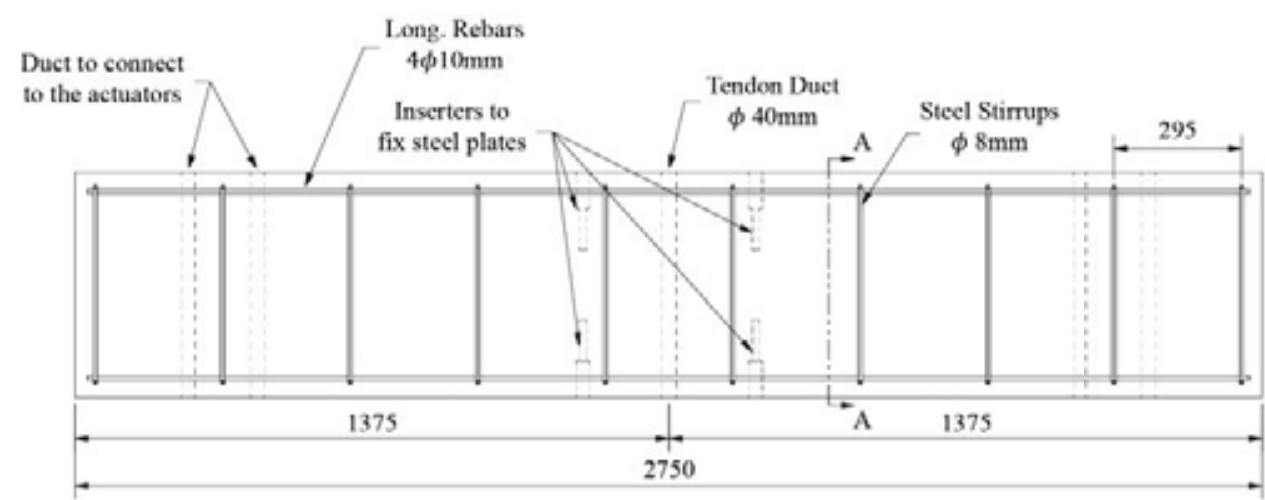

BEAM ELEVATION

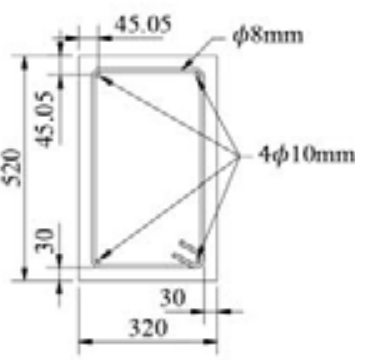

SECTION A-A

Figure 3: Cap-beam elevation and cross-section (dimensions in $\mathrm{mm}$ )

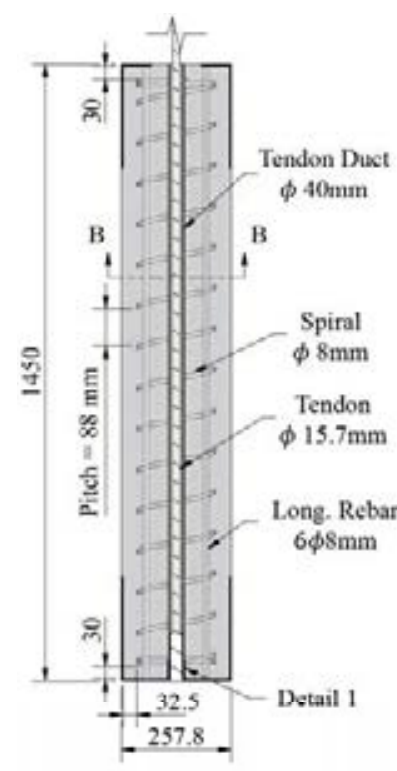

COLUMN FIEVATION

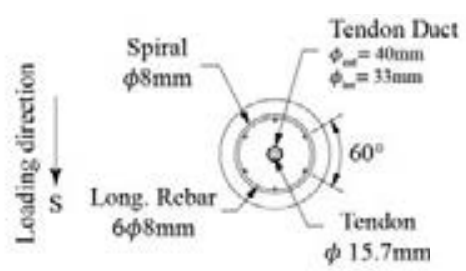

SECTION B-B

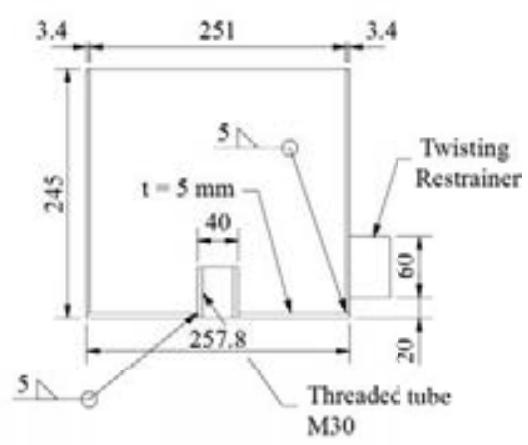

DETAIL 1 - COL/JACKET

Figure 4: Column elevation and critical cross-sections (dimensions in $\mathrm{mm}$ )

\subsection{Restraining System}

The stiffness of the restraining system $\left(k_{r e s}\right)$ was obtained based on the force deformation curve discussed in [30], under the assumption that the pre uplift deformation is negligible. For small rotations, one can linearize and get the desired stiffness of the restraining system as:

$$
k_{\text {res }}=\frac{4 V}{\alpha b} \cdot \frac{(\lambda-1)}{\lambda}
$$

where $V$ is the total vertical loading acting on the column plus half of its self-weight, $\alpha$ is the slenderness angle of the column (i.e. width to height ratio), $b=257.8 \mathrm{~mm}$ is the diameter of the 
column, and $\lambda$ is the factor by which the displacement capacity of a free rocking column with equivalent slenderness should be increased (i.e. $\lambda=u_{\text {cap }} / b$ ).

The tests were performed under a vertical load $V=52.2 \mathrm{kN}$ that would correspond to a normalized axial load $(v)$ of $5 \%$ in the columns, which is typical for bridge columns. Then, Eq. (1) gives the target stiffness of the restraining system that would result in doubling the displacement capacity of the column $(\lambda=2): k_{r e s}=2302 \mathrm{kN} / \mathrm{m}$. The restraining system was composed of a tendon with nominal cross-section area of $150 \mathrm{~mm}^{2}$ in series with 11 disc springs of individual deformation capacity of $5.6 \mathrm{~mm}$ (Fig. 2). This design gives an overall stiffness of the restraining system of $2613 \mathrm{kN} / \mathrm{m}$ until $44 \mathrm{~mm}$ axial displacement.

The tendon had threaded sockets at its ends. Therefore, it was anchored in the bottom end of the column, as Detail 1 of Fig. 4 shows. The other end was anchored at the top of the springs with a nut. The tendon was unbonded through its entire length.

\subsection{Steel Reinforcement}

The column reinforcement was designed to resist the internal moment generated when the column rotates to a displacement equal to $2 b=515.6 \mathrm{~mm}$. It resulted in a longitudinal reinforcement composed of 6 B500B rebars of $8 \mathrm{~mm}$-diameter $\left(A_{s}=3.02 \mathrm{~cm}^{2}\right)$ distributed uniformly along the circular perimeter of the column. The longitudinal reinforcement was welded on the steel plate at the column ends.

The transverse reinforcement comprised an $8 \mathrm{~mm}$-diameter B500B spiral, which is the minimum according to Eurocode $2[50]\left(A_{s w} / s=0.022 \mathrm{~cm}^{2} / \mathrm{cm}\right)$.

\subsection{Column steel parts}

The steel jackets consisted of a S355 steel tube $3.4 \mathrm{~mm}$-thick, $245 \mathrm{~mm}$-high and $257.8 \mathrm{~mm}$ in external diameter. The steel tube was welded in its base to a S355 steel plate $5 \mathrm{~mm}$-thick. The detailing of the steel plate is different in the bottom and top part of the column. In the steel plate placed at the bottom of the column, a threaded steel tube was welded to it for anchoring the tendon. In the top part, a circular annular plate was used to allow casting of the column.

\subsection{Slide and twist restrainers}

To limit sliding, the steel plates fixed to the ground and to the cap-beam were equipped with sliding restrainers that limited sliding to $5 \mathrm{~mm}$ in each direction (Fig. 5).

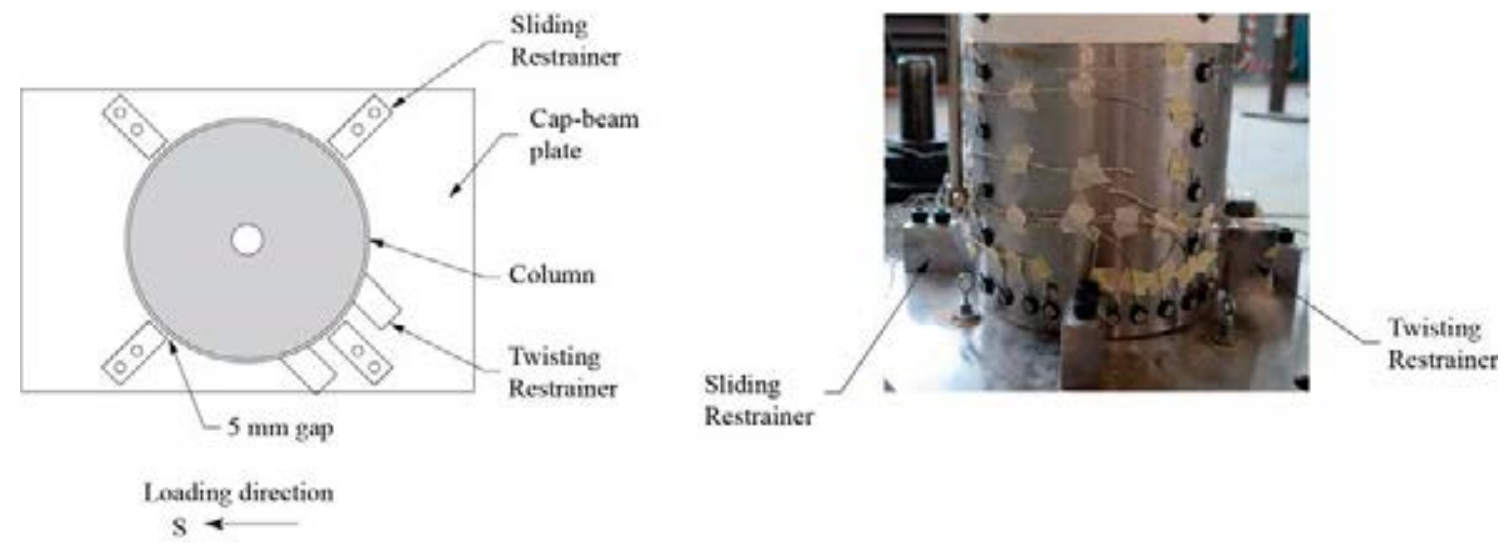

Figure 5: Schematic illustration of the motion restrainers 


\subsection{Concrete mix}

The columns were casted in-house using a commercial dry mixture of self-compacting concrete of strength class $\mathrm{C} 30 / 37\left(f_{c k}=30 \mathrm{MPa}\right)$. Although the water/cement ratio suggested in the pack of the dry mixture was initially respected, the concrete workability was not the one expected, and more water had to be added to the mixture.

Three standard cylindrical specimens of $150 \mathrm{~mm}$-diameter and $300 \mathrm{~mm}$-high were casted to define the strength and Young's modulus of the concrete. The measured mean strength and Young's modulus of the specimen were 45.4 MPa and $30 \mathrm{GPa}$, respectively.

\section{TEST SETUP AND INSTRUMENTATION}

The test setup is shown in Fig. 6a. It consisted of two vertical actuators and a horizontal actuator. The three actuators applied forces or displacements to a steel beam, which was connected to the cap-beam with short wide flange steel beams. The steel beam is constrained, and out-of-plane displacement is not allowed.

The setup kept the vertical force applied to the column constant and equal to $52.20 \mathrm{kN}$, simulating the gravitational loads of the super-structure. The rotation of the cap and steel beam was kept constant and equal to zero. For the cyclic test, the horizontal actuator applied the displacements defined in the loading protocol shown in Fig. 6b. The loading protocol consisted of two consecutive cycles of same drift ratio, followed by a subsequent cycle of 1.25 times the previous drift ratio. In total, the columns were subjected to 18 sets of two cycles each. The loading protocol was based on the American Concrete Institute recommendations. Since the most recent report [51] specifies that the drift ratio must be increased based on the yield strain, the increase of the drift ratios was based on an older report [52].

The displacement of the column and cap-beam were measured by an optical measurement device that tracks the positions of markers fixed in the specimen. The forces and strokes of all actuators were recorded by load cells and lasers installed on them. A load cell was also installed in series with the springs and tendon, recording the forces in the restraining system. Rosettes measured the strain in the steel jacket.

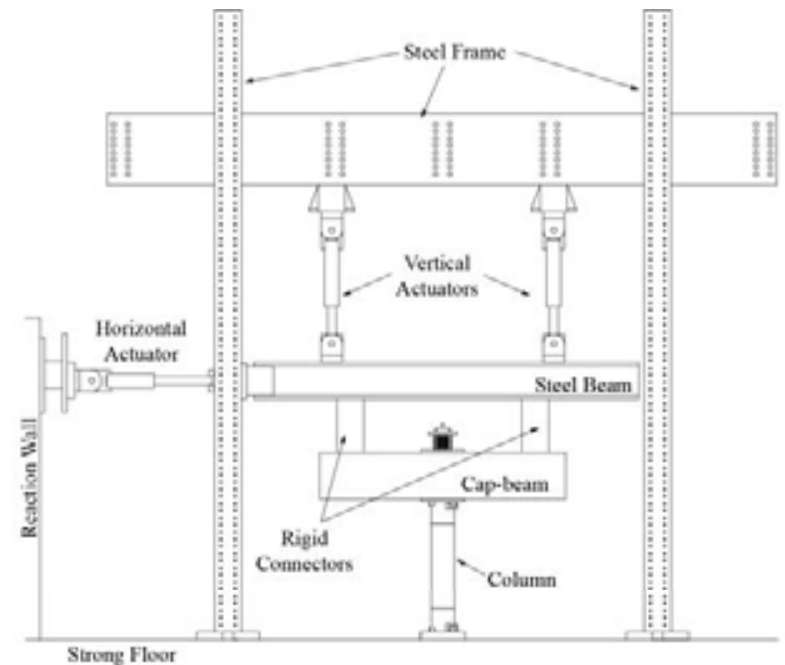

(a)

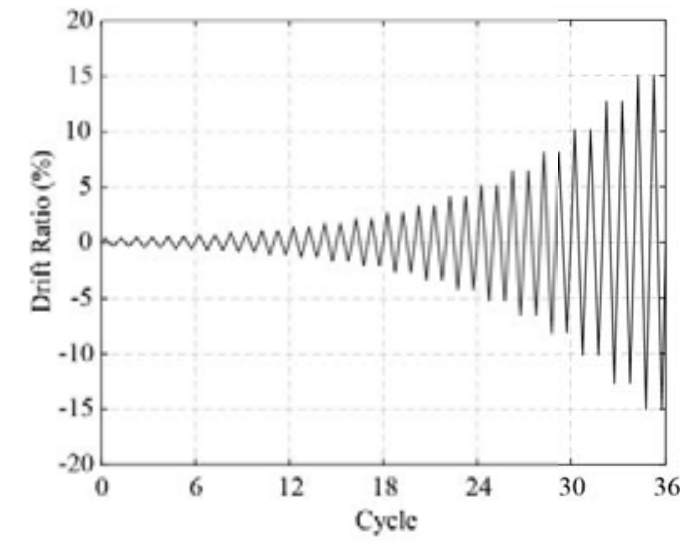

(b)

Figure 6: (a) Test setup, and (b) Cyclic time history. 


\section{FORCE-DRIFT LOOPS}

Fig. 7 presents the force-drift response for low drift ratios (up to 1.1\%), medium drift ratios (up to $4.2 \%$ ), and high drift ratios (up to $15 \%$ ). The drift ratio is defined herein as the ratio between the horizontal displacement of the beam and the height of the column $(1450 \mathrm{~mm})$.

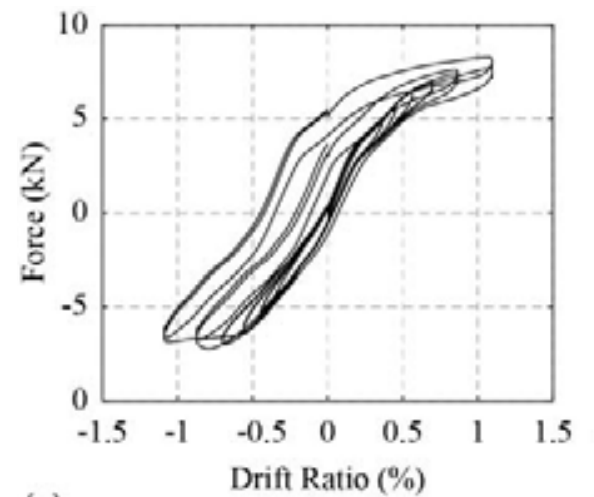

(a)

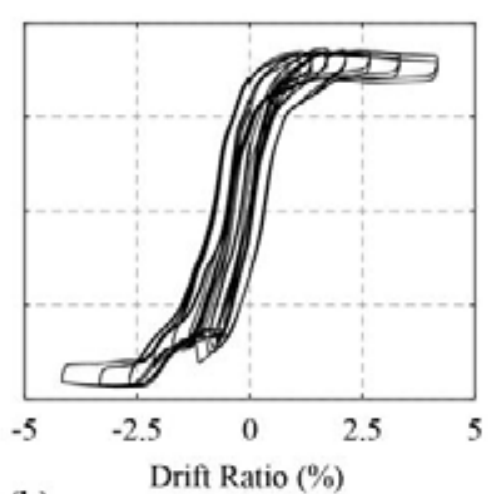

(b)

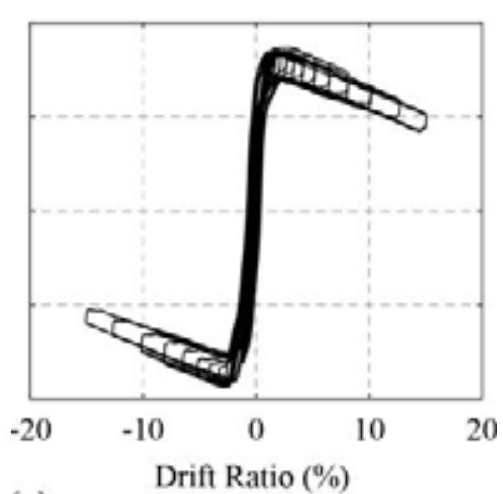

(c)

Figure 7. Force-drift relation for: (a) low drift ratio, (b) medium drift ratio, and (c) high drift ratio

One can observe that the column presents almost no strength reduction. It is not clear whether the energy dissipation deduced from the area of the loops comes from the column itself or from friction of the set up. More tests are currently performed to quantify the friction of the spring and of the setup itself. In any case, there was only minimal damage in the columns, so it is difficult to imagine a physically plausible way of energy dissipation within the column.

Sliding and twisting of the specimen were limited, but not zero. Both motions could be observed and measured with the optical position trackers fixed in several points of the column and cap-beam. Twisting was negligible. Sliding, however, was observed and it is also depicted in the force-drift relations (Fig.7a-b).

Fig. 8 shows the envelope of the force-drift response. As the protocol defined two cycles per drift amplitude, the envelope for both cycles is plotted. The same plot shows the envelope predicted by rigid body calculations, assuming a rigid column with same dimensions of the tested column ( $257.8 \mathrm{~mm}$-diameter and $1450 \mathrm{~mm}$-height), constant vertical load of $52.20 \mathrm{kN}$ and restraining system stiffness of $2613 \mathrm{kN} / \mathrm{m}$. The flexibility of the tested system only causes a slight deviation from the rigid body model that is non-negligible only for very small drift ratios, essentially before the column uplifts.

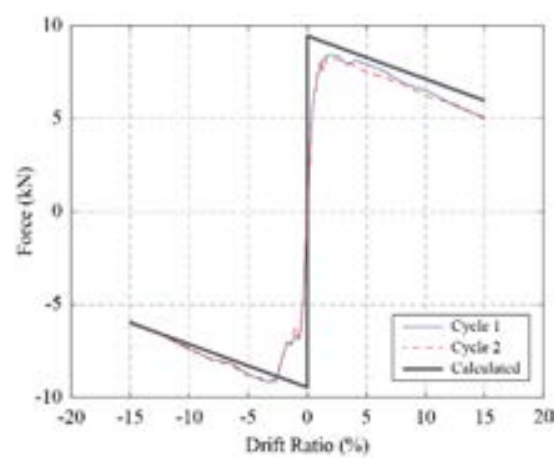

Figure 8: Force-drift envelope 


\section{OBSERVED DAMAGE}

At the end of the test, almost no damage could be noticed at the column (Fig. 9c-d). No cracks or spalling of the column was observed. The top steel jacket, however, presented some minimal damage. The steel plate slightly bent (Fig. 9a) and the steel tube presented a dent (Fig. 9b), as a result of local buckling. Both damages occurred close to the end of the very end of the column, at drift of $12.7 \%$. The bottom steel jacket did not present any damage visually observed, as the contact force there is smaller.

(a)

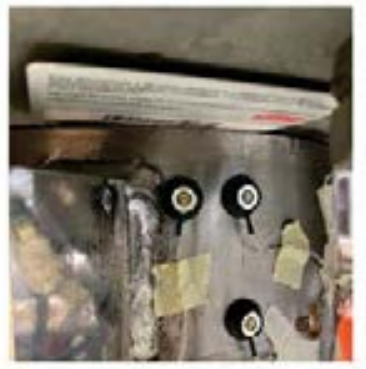

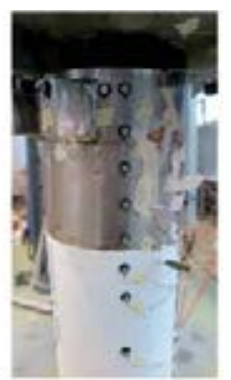

(c)

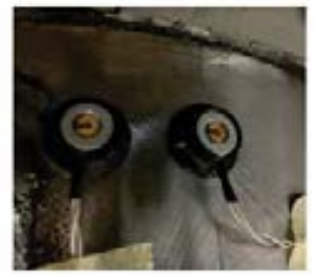

(b)

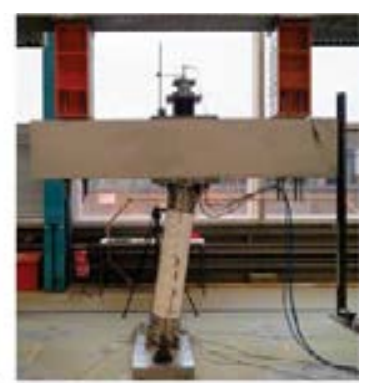

(d)

Figure 9: (a) Bending of the steel plate, and (b) dent of the steel tube of the steel jacket at the end of test; (c) column, and (d) overall view of the system at $15 \%$ drift ratio.

\section{CONCLUSIONS}

Negative stiffness restrained rocking columns can be used in bridge design in an effort to reduce the design moment of the foundation and possibly save the piles. Such a system using disc springs in series with a steel tendon as a restraining system was tested to drift ratios up to $15 \%$. Negligible visual damage was observed. Since the force deformation loops did not change during the tests, no strength degradation was observed. Thus the system is resilient.

As the aim of the proposed design approach is to reduce the design moment of the foundation and avoid the huge pile foundations that are often designed in seismic areas, the system contributes to sustainable seismic design.

\section{ACKNOWLEDGEMENT}

This work was supported by the ETH Zurich under grant ETH-10 18-1. 


\section{REFERENCES}

[1] M. J. N. Priestley and J. R. Tao, Seismic Response of Precast Prestressed Concrete Frames With Partially Debonded Tendons. PCI J., 38 (1), 58-69, 1993.

[2] W. C. Stone, S. Geraldine, and J. F. Stanton, Beam-Column Concrete Connections Subjected to Cyclic Loading. ACI Struct. J., 92 (2), 229-249, 1995.

[3] P. M. Davis, T. M. Janes, M. O. Eberhard, and J. F. Stanton, Unbonded pre-tensioned columns for bridges in seismic regions, Rep. No. 2012/04, Pacific Earthquake Engineering Research Center, Berkeley, CA, 2012.

[4] G. Finnson, Unbonded Pre-Tensioned Bridge Columns with Hybrid Fiber-Reinforced Concrete Shells. University of Washington, 2013.

[5] O. S. Haraldsson, T. M. Janes, M. O. Eberhard, and J. F. Stanton, Seismic Resistance of Socket Connection between Footing and Precast Column. J. Bridg. Eng., 18 (9), 910-919, 2013.

[6] Z. B. Haber, M. S. Saiidi, and D. H. Sanders, Seismic performance of precast columns with mechanically spliced column-footing connections. ACI Struct. J., 111 (3), 639650, 2014.

[7] M. J. Ameli, J. E. Parks, D. N. Brown, and C. P. Pantelides, Seimic evaluation of grouted splice sleeve connections for reinforced precast concrete column-to-cap beam joints in accelerated bridge construction. PCI J., 60 (2), 80-103, 2015.

[8] G. Guerrini, J. I. Restrepo, M. Massari, and A. Vervelidis, Seismic Behavior of Posttensioned Self-Centering Precast Concrete Dual-Shell Steel Columns. J. Struct. Eng., 141 (4), 04014115, 2015.

[9] M. Tazarv and M. S. Saiidi, UHPC-filled duct connections for accelerated bridge construction of RC columns in high seismic zones. Eng. Struct., 99, 413-422, 2015.

[10] H. Tran, "Drilled Shaft Socket Connections for Precast Columns in Seismic Regions," University of Washington, 2015.

[11] T. Thonstad, I. M. Mantawy, J. F. Stanton, M. O. Eberhard, and D. H. Sanders, Shaking Table Performance of a New Bridge System with Pretensioned Rocking Columns. J. Bridg. Eng., 21 (4), 04015079, 2016.

[12] T. Thonstad, B. J. Kennedy, J. A. Schaefer, M. O. Eberhard, and J. F. Stanton, Cyclic Tests of Precast Pretensioned Rocking Bridge-Column Subassemblies. J. Struct. Eng., 143 (9), 04017094, 2017.

[13] J. B. Mander and C. T. Cheng, Seismic Resistance of Bridge Piers Based on Damage Avoidance Design. Rep. No. NCEER-97-0014, National Center for Earthquake Engineering and Research, Buffalo, NY, 1997.

[14] M. Mashal and A. Palermo, Low-Damage Seismic Design for Accelerated Bridge Construction. J. Bridg. Eng., 24 (7), 04019066, 2019.

[15] J. Jia, K. Zhang, M. S. Saiidi, Y. Guo, S. Wu, K. Bi, X. Du, Seismic evaluation of precast bridge columns with built-in elastomeric pads. Soil Dyn. Earthq. Eng., 128, 105868, 2020.

[16] R. Liu and A. Palermo, Ten Years of Experiments on Bridges Using Resilient DamageResistant Systems and Accelerated Construction Techniques. Struct. Eng. Int., 30 (2), 
224-231, 2020.

[17] J. T. Hewes and M. J. N. Priestley, Seismic design and performance of precast concrete segmental bridge columns. Rep No. SSRP-2001/25, California Department of Transportation, Sacramento, California, 2002.

[18] S. L. Billington and J. K. Yoon, Cyclic Response of Unbonded Posttensioned Precast Columns with Ductile Fiber-Reinforced Concrete. J. Bridg. Eng., 9 (4), 353-363, 2004.

[19] A. Palermo, S. Pampanin, and D. Marriott, Design, Modeling, and Experimental Response of Seismic Resistant Bridge Piers with Posttensioned Dissipating Connections. J. Struct. Eng., 133 (11), 1648-1661, 2007.

[20] D. Marriott, S. Pampanin, and A. Palermo, Quasi-static and pseudo-dynamic testing of unbonded post-tensioned rocking bridge piers with external replaceable dissipaters. Earthq. Eng. Struct. Dyn., 38, 331-354, 2009.

[21] E. E. Matsumoto, M. C. Waggoner, M. E. Kreger, J. Vogel, and L. Wolf, Development of a precast concrete bent-cap system. PCI J., 53 (3), 74-99, 2008.

[22] J. B. K. Pang, M. O. Eberhard, and J. F. Stanton, Large-Bar Connection for Precast Bridge Bents in Seismic Regions. J. Bridg. Eng., 15 (3), 231-239, 2010.

[23] J. I. Restrepo, E. E. Matsumoto, and M. J. Tobolski, Development of a Precast Bent Cap System for Seismic Regions, NCHRP Rep. No. 681, Transportation Research Board, Washington, DC, 2011.

[24] S. White and A. Palermo, Quasi-Static Testing of Posttensioned Nonemulative Column-Footing Connections for Bridge Piers. J. Bridg. Eng., 21 (6), 04016025, 2016.

[25] P. Sideris, A. J. Aref, and A. Filiatrault, Quasi-Static Cyclic Testing of a Large-Scale Hybrid Sliding-Rocking Segmental Column with Slip-Dominant Joints. J. Bridg. Eng., 19 (10), 04014036, 2014.

[26] P. Sideris, A. J. Aref, and A. Filiatrault, Large-Scale Seismic Testing of a Hybrid Sliding-Rocking Posttensioned Segmental Bridge System. J. Struct. Eng., 140 (6), 04014025, 2014.

[27] P. Sideris, A. J. Aref, and A. Filiatrault, Experimental Seismic Performance of a Hybrid Sliding-Rocking Bridge for Various Specimen Configurations and Seismic Loading Conditions. J. Bridg. Eng., 20 (11), 04015009, 2015.

[28] N. Makris and M. Vassiliou, Planar rocking response and stability analysis of an array of free-standing columns capped with a freely supported rigid beam. Earthq. Eng. Struct. Dyn., 42, 431-449, 2012.

[29] N. Makris and M. F. Vassiliou, Are Some Top-Heavy Structures More Stable? J. Struct. Eng., 140 (5), $06014001,2014$.

[30] N. Reggiani Manzo and M. F. Vassiliou, Simplified analysis of bilinear elastic systems exhibiting negative stiffness behavior. Earthq. Eng. Struct. Dyn., 50 (2), 580-600, 2021.

[31] Y. Xie, J. Zhang, R. DesRoches, and J. E. Padgett, Seismic fragilities of single-column highway bridges with rocking column-footing. Earthq. Eng. Struct. Dyn., 48 (7), 843864, 2019.

[32] A. I. Giouvanidis and Y. Dong, Seismic loss and resilience assessment of single- 
column rocking bridges- Bull. Earthq. Eng., 18 (9), 4481-4513, 2020.

[33] M. Sieber, S. Klar, M. F. Vassiliou, and I. Anastasopoulos, Robustness of simplified analysis methods for rocking structures on compliant soil. Earthq. Eng. Struct. Dyn., 49 (14), 1388-1405, 2020.

[34] I. M. Thomaidis, A. J. Kappos, and A. Camara, Dynamics and seismic performance of rocking bridges accounting for the abutment-backfill contribution. Earthq. Eng. Struct. Dyn., 49 (12), 1161-1179, 2020.

[35] E. G. Dimitrakopoulos and A. I. Giouvanidis, Seismic Response Analysis of the Planar Rocking Frame. J. Eng. Mech., 141 (7), 04015003, 2015.

[36] A. I. Giouvanidis, Non-smooth seismic response analysis of the rocking frame. The Hong Kong University, 2015.

[37] A. Agalianos, A. Psychari, M. F. Vassiliou, B. Stojadinovic, and I. Anastasopoulos, Comparative assessment of two rocking isolation techniques for a motorway overpass bridge. Front. Built Environ., 3, 1-19, 2017.

[38] M. F. Vassiliou, K. R. Mackie, and B. Stojadinovic, A finite element model for seismic response analysis of deformable rocking frames. Earthq. Eng. Struct. Dyn., 46 (3), 447-466, 2016.

[39] M. F. Vassiliou, S. Burger, M. Egger, J. A. Bachmann, M. Broccardo, and B. Stojadinovic, The three-dimensional behavior of inverted pendulum cylindrical structures during earthquakes. Earthq. Eng. Struct. Dyn., 46 (14), 2261-2280, 2017.

[40] M. F. Vassiliou, M. Broccardo, C. Cengiz, M. Dietz, L. Dihoru, S. Gunay, K. M. Mosalam, G. Mylonakis, A. Sextos, B. Stojadinovic, Shake table testing of a rocking podium: Results of a blind prediction contest. Earthq. Eng. Struct. Dyn., 50 (4), 1043$1062,2021$.

[41] M. F. Vassiliou, Seismic response of a wobbling 3D frame. Earthq. Eng. Struct. Dyn., 47 (5), 1212-1228, 2018.

[42] N. Reggiani Manzo and M. F. Vassiliou, Displacement-based analysis and design of rocking structures. Earthq. Eng. Struct. Dyn., 48 (14), 1613-1629, 2019.

[43] N. Makris and M. F. Vassiliou, Dynamics of the Rocking Frame with Vertical Restrainers. J. Struct. Eng., 141 (10), 04014245, 2015.

[44] M. F. Vassiliou and N. Makris, Dynamics of the Vertically Restrained Rocking Column. J. Eng. Mech., 141 (12), 04015049, 2015.

[45] R. Thiers-Moggia and C. Málaga-Chuquitaype, Seismic protection of rocking structures with inerters. Earthq. Eng. Struct. Dyn., 48 (5), 528-547, 2019.

[46] Y. L. Zhou, Q. Han, X. L. Du, J. Q. Zhang, S. S. Cheng, and J. Y. Chen, Additional viscous dampers for double-column rocking bridge system: Seismic response and overturning analysis. Soil Dyn. Earthq. Eng., 141, 106504, 2021.

[47] S. Polyakov, Design of Earthquake Resistant Structures. Mir. Publishers., 1974.

[48] J. A. Bachmann, M. F. Vassiliou, and B. Stojadinovic, Dynamics of rocking podium structures. Earthq. Eng. Struct. Dyn., 46 (14), 2499-2517, 2017.

[49] J. A. Bachmann, M. F. Vassiliou, and B. Stojadinovic, "Rolling and rocking of rigid uplifting structures,” Earthq. Eng. Struct. Dyn., 48 (14), 1556-1574, 2019. 
[50] CEN, Eurocode 2: Design of concrete structures - Part 1-1: General rules and rules for buildings. Comité Européen de Normalisation, Brussels, Belgium, 2004.

[51] ACI, Guide for Testing Reinforced Concrete Structural Elements under Slowly Applied Simulated Seismic Loads. Farmington Hills, MI, 2013.

[52] ACI, Acceptance criteria for moment frames based on structural testing. Farmington Hills, MI, 2001. 